\title{
Compression after impact of thin composite laminates
}

\author{
S. Sanchez-Saez, E. Barbero, R. Zaera, C. Navarro * \\ Department of Continuum Mechanics and Structural Analysis, Carlos III University of Madrid, Avda. de la Universidad 30, \\ 28911 Leganés, Madrid, Spain
}

\begin{abstract}
The damage tolerance of various lay ups of thin carbon/epoxy laminates (1.6 $2.2 \mathrm{~mm}$ thick) is examined by compression after impact (CAI) tests, using a new testing device which adapts to the thicknesses of the specimens and does not require tabs nor any modification of the specimen geometry. The compression stress state was not modified by the presence of the device, as was verified by numerical simulation. With this device, CAI tests were done of different carbon/epoxy laminate lay ups (quasi isotropic, cross ply and woven) and the values of the residual strength and the normalized residual strength of the laminates were obtained as a function of the impact energy. The woven laminate was found to offer the highest residual strength under all the impact energies, and the quasi isotropic laminate the least loss of normalized strength as the impact energy was raised.
\end{abstract}

Keywords: A. Carbon fibres; B. Strength; C. Damage tolerance; C. Laminates

\section{Introduction}

Carbon fiber/epoxy laminates are widely used in aeronautic and aerospace structural components mainly because of their excellent specific mechanical properties. They may suffer damage during their manufacture, assembly, maintenance or service life, caused by different types of impact, of which low-energy impact is considered the most dangerous [1,2], because the damage may escape detection in a routine visual inspection of the impacted surface of the component [3]. The impact energy causing visible damage to the component may be well above that which has a significant effect on the mechanical properties $[4,5]$. Delamination is probably the most serious problem, given the difficulty of its visual detection and the extent to which it lowers the mechanical properties [6]. The greatest reduction is that

\footnotetext{
* Corresponding author. Tel.: +349162494 91; fax: +349162494 30 .

E mail address: carlos.navarro@uc3m.es (C. Navarro).
}

of the compression strength $[7,8]$ which may be up to $4060 \%$ of that of an undamaged structural element [9]. So damage tolerance is an important factor in the design of aeronautic and aerospace components made of laminated materials.

Damage tolerance in laminates is usually studied by determining the effect of different impact energies on their residual strength, the compression after impact (CAI) test being the experimental test of components damaged by low energy impact. The global testing process has two steps: in the first, the specimen is subjected to low-energy transverse impact that generates a certain degree of damage inside the laminate; then the damaged specimen is tested in in-plane compression to determine its residual strength. CAI tests must be carried out in a device that avoids global buckling of the impacted specimens, so that failure comes as the delamination progresses with the local buckling of the sublaminates produced by impact.

Several organizations and companies have published recommendations for the CAI test (NASA [10], 
Boeing [11], SACMA [12], CRAG [13]), but there is no universal standard (ASTM or ISO) that would state the specimen geometry and the test variables. Most of the tests to generate laminate damage are done with a drop weight tower testing device $[1,1419]$ that reproduces the impact of a large mass at relatively low velocity (a few meters per second). The size of the specimen and the clamping system vary from one study to another but the devices and the procedures are similar. However, notable differences are found in the subsequent compression tests of the damaged specimens. The large aeronautic and aerospace companies (NASA, Boeing) normally use thick specimens $(>3 \mathrm{~mm})$ with their top and bottom edges clamped, and the lateral edges supported, to avoid failure by global buckling of the specimen which is usually narrow. In the test adopted by CRAG, the specimen is fitted with tabs at each end. These methods call for very large specimens, so a great deal of material would be needed. On the other hand, in many aeronautic and aerospacial applications, the laminates used in structural components are thin $(1.52 \mathrm{~mm})$ such as those in the cryogenic tanks of $\mathrm{H}_{2}$ of reusable launch vehicles [20 22] and in the fan blade of a turbojet engine [23]. This means that the data obtained from the above-mentioned tests might be inapplicable to the actual structure since the damage mode depends in part on the thickness of the mechanical component. Prichard and Hogg [9] used these tests with small thin specimens, but other authors [24] have shown that at thicknesses below $2 \mathrm{~mm}$, the same methods can produce local crushing damage in the loading zone and generate erroneous residual strength values. Tabs have been proposed for thin specimens as a method of avoiding this problem [25] and in other studies [24,26], antibuckling plates are used in addition; this avoids global buckling of the specimen but does not prevent the local buckling of the sublaminates generated by the impact. The antibuckling plates have a centre hole so that they do not alter the impact damage surface. The objection to these methods is that specimens with end tabs need grips to be fixed, as in tensile tests, and they have to be narrow, which could mean a change of their geometry before the compression test [27]. Also an accurate alignment of the specimen is required and the use of tabs makes the test more complicated. To avoid these drawbacks, some authors have used loading plates with a slot in which the specimen is placed between antibuckling plates [15]. Other methods use a device that can be adapted to the thickness of the impacted specimens and does not require either lateral guides or antibuckling plates, the specimen being sized to avoid global buckling [28].

There are, then, problems in testing damaged composite materials in compressive conditions. The test methods of aeronautic companies and other organizations recommend the use of large specimens of thickness above $3 \mathrm{~mm}$. This requires a great deal of material and a high cost, and the test specimens do not always correspond to the actual material of the structure. There is no generally accepted method of testing small specimens of less than $3 \mathrm{~mm}$ thickness; most proposed methods have to use tabs and narrower specimens, and this implies a change in the specimen geometry in some cases and further complexity in the test.

Several authors have studied the reduction of the compression residual strength, but most have centered on quasi-isotropic laminates $[1,4,14 \quad 16,19,24,2931]$ and a few on other tape lay-ups and woven laminates (two-dimensional fabric) [27,32 35].

In this work, the damage tolerance of different lay-ups of carbon fibre/epoxy laminates, of thicknesses between 1.6 and $2.2 \mathrm{~mm}$, was considered. Two tape laminates (quasi-isotropic and cross-ply) and a woven laminate were tested. The residual strength and the normalized residual strength were obtained and examined to find how these are modified by changes of the impact energy. A new device for the CAI tests of the thin laminates was designed, which avoids the above mentioned problems. Numerical simulation showed that in a uniaxial compression test, the stress is not altered with this new device.

\section{Experimental set-up}

\subsection{Description of the CAI device}

The device used to test different thin laminates (1.5 $2.2 \mathrm{~mm}$ ) had to adjust to their thicknesses, and avoid altering their geometry with a narrowing of the specimens that would modify the impact damage. The use of tabs was ruled out to simplify the test.

Considering these requirements and trying to avoid the problems of other investigations, several devices were designed (Fig. 1). One of these, similar to those of the aeronautical groups (SACMA, NASA or Boeing) and to that of Duarte et al. [15], adapted to the geometry of the impacted specimens used in the study, is shown in

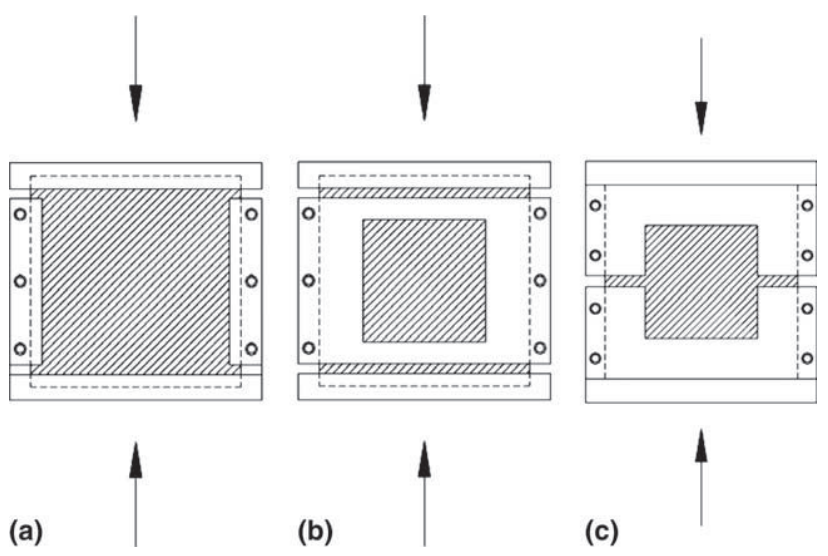

Fig. 1. CAI devices developed. 


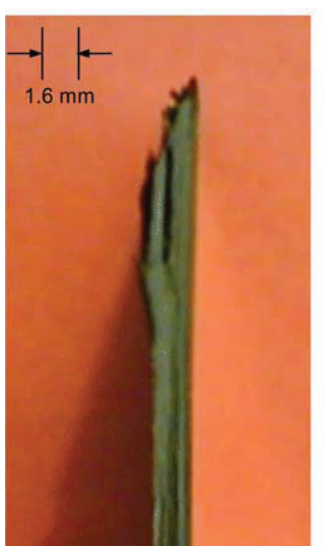

(a)

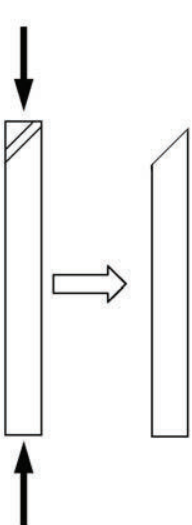

(b)
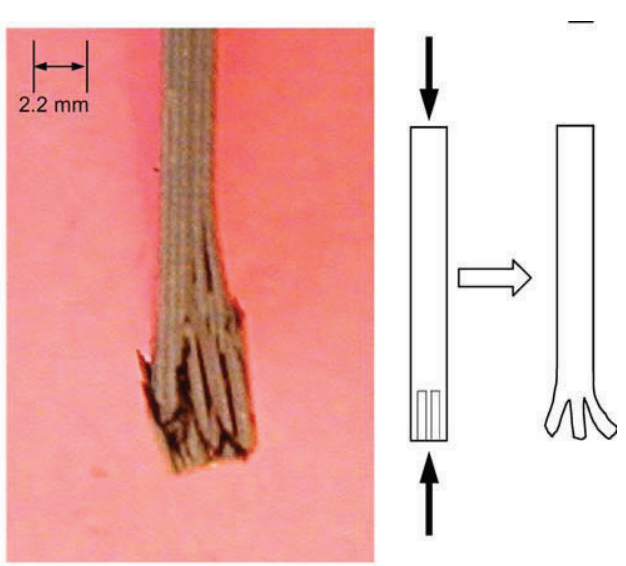

(b)

Fig. 2. Failure modes in CAI tests using a device similar to those proposed by SACMA, NASA and BOEING. (a) Failure by compression shear; (b) Failure by end crushing brooming.

Fig. 1(a). After the CAI test of the specimens, compression shear failure in the free area between the supported and the clamped zones, near the top loading plate (Fig. 2(a)) was observed, and in several specimens, crushingbrooming failure was observed (Fig. 2(b)) at the other end, as Prichard and Hogg [9] and Liu et al. [25] had found.

Another set-up is shown in Fig. 1(b). It used two antibuckling plates with a square central opening, similar to those proposed by Sjöblom and Hwang [26], and by Nettles and Hodge [24]. Failure in the specimen was by compression shear in one of the free zones, between the loading and the anti-buckling plates (Fig. 3). The specimen fracture occurred by this mechanism and not by local buckling of the delaminated areas.

A third set-up, shown in Fig. 1(c), avoids these problems. Each of two antibuckling plates was modi-

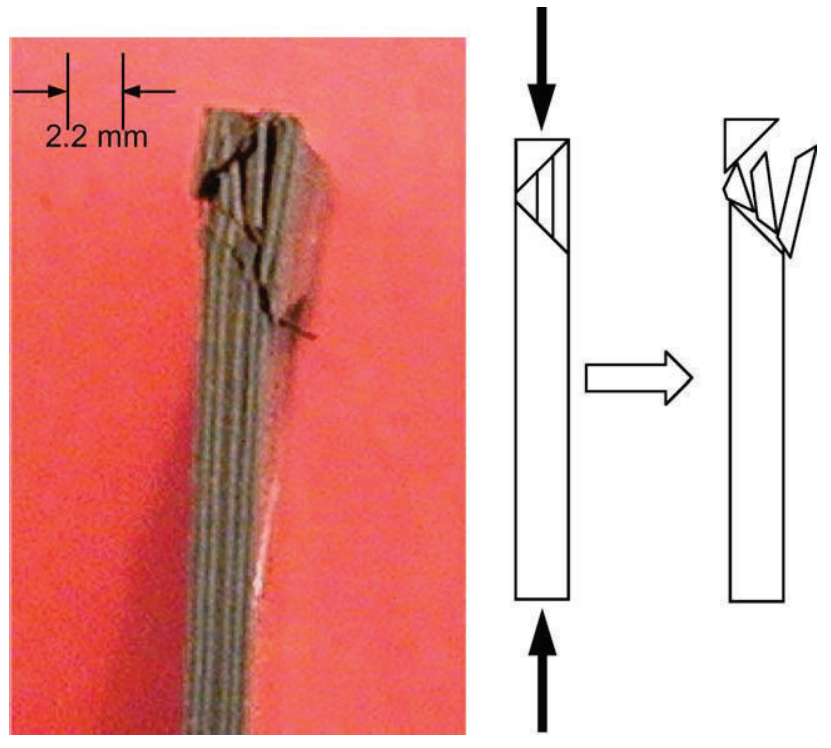

Fig. 3. Failure by compression shear in CAI tests using a device based on those proposed of Sjoblom Hwang and Nettles Hodge. fied by splitting it into two parts, an upper and a lower plate. The two rear plates were welded to the loading plates. Both halves had a rectangular opening in the middle that left the central surface of the specimen free and did not modify the surfaces damaged by the impact. The dimensions of the set-up were adapted to the geometry of the specimens $(78 \times 78 \mathrm{~mm})$. The antibuckling halves measured $111.5 \times 37 \mathrm{~mm}$ and the central opening $50 \times 26.5 \mathrm{~mm}$. The specimen was placed in the set-up and each of the front antibuckling plates was screwed to the rear plates by four hand-tightened screws, which allowed free compression of the specimen and avoided global buckling. A free zone of 4 $\mathrm{mm}$ is left between the upper and lower antibuckling plates. The positioning and alignment of the specimen in the loading direction is ensured in the test device when it is placed in the hydraulic machine, by the union of each part of the rear antibuckling plate to the loading plates (Fig. 4).

With this set-up, failure occurred in the zone damaged by local buckling of the sublaminate produced by the impact (Fig. 5).

Fig. 6 shows how specimen failure was caused by the delamination extension perpendicular to the loading direction.

\subsection{Influence of the antibuckling plates on the stress distribution}

To determine the influence of antibuckling plates on the specimen stress distribution, a numerical simulation was made of an ortotropic laminate $[0 / 90]_{3 \mathrm{~S}}$ subjected to compression in $0^{\circ}$ direction, using the finite element ABAQUS/Standard code [36]. The $78 \times 78 \mathrm{~mm}$ specimen was discretized by three-dimensional brick elements of eight nodes and reduced integration, making 40 elements on each edge and 12 elements through the thickness, one for each ply (Fig. 6). 


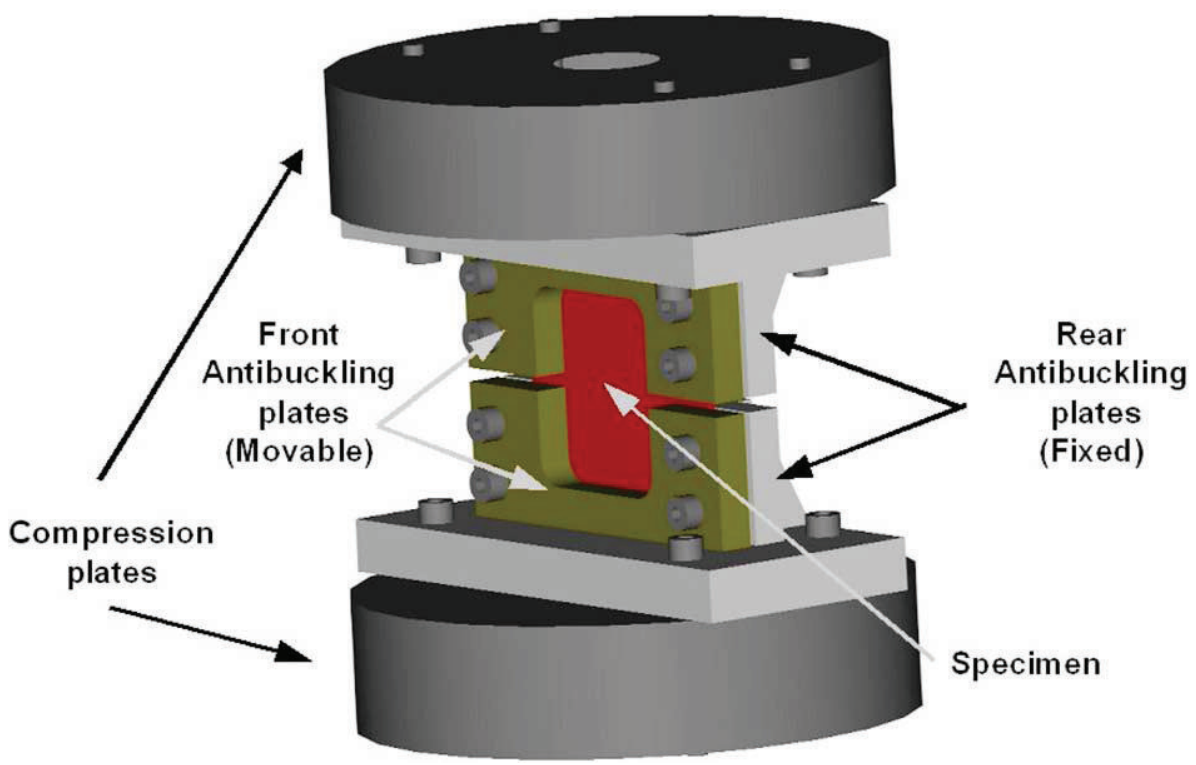

Fig. 4. New CAI set up developed in this study.

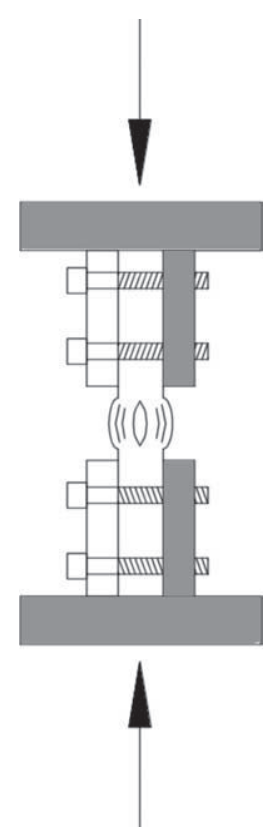

Fig. 5. Local buckling of the sublaminates induced by impact on the specimen, using the new device.

The material was considered ortotropic, with the elastic constants shown in Table 1 , representative of a tape lamina AS4/3501-6 at room temperature.

In the nodes of the lower edge of the specimen, displacement was blocked in the loading direction, while in those of the upper edge this was $0.8 \mathrm{~mm}$, the maximum recorded in the experimental tests. To account for the influence of the antibuckling plates, the following boundary conditions were applied on the specimen surface: the nodes of specimen zones in contact with the antibuckling plates (shaded in Fig. 7) were given a spring perpendicular to the laminate surface. Discounting the possible bending of the antibuckling plates and therefore assuming that they remain flat during the test, the rigidity of each spring was obtained by an even distribution of the axial stiffness of the screws securing the opposite antibuckling plates.

The antibuckling plates were placed to restrict outof-plane movement of the specimen. The stiffness of the screws securing the opposite antibuckling plates was not very high in order to allow an increase of the specimen thickness due to the Poisson effect. Fig. 8 shows the contour of normal stress in the compression direction in $0^{\circ}$ and $90^{\circ}$ plies (the results in the laminate plies with the same fibre orientation being identical). The contact normal force between plates and specimen did not distort the stress distribution significantly, as it is desirable in this kind of test. The effects of the screws were modeled by springs of appropriate stiffness and consequently only small differences in the stress contours were observed. In the ply with the fibres orientated in the loading direction (Fig. 8(a)), the antibuckling plates do not affect the stress state in the zones of the specimen that are in contact with them; the variations are of about $2 \%$ in the centre and $4 \%$ at the edge as compared to those of a theoretical situation of uniaxial compression without the antiblucking plates. This was verified by an additional simulation in which the springs were eliminated, leaving both sides of the laminate free, imposing the same boundary conditions on its upper and lower surfaces and restricting the displacement perpendicular to the laminate plane in the nodes of the symmetry surface (Fig. 9). 


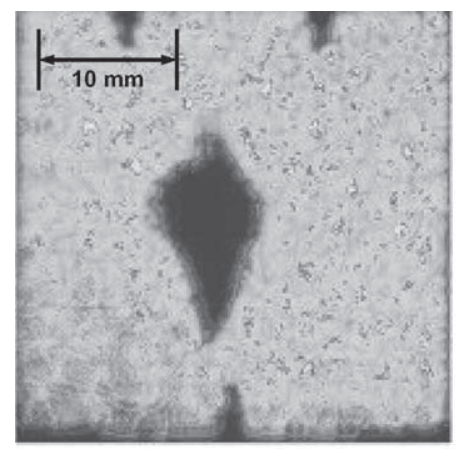

(a)

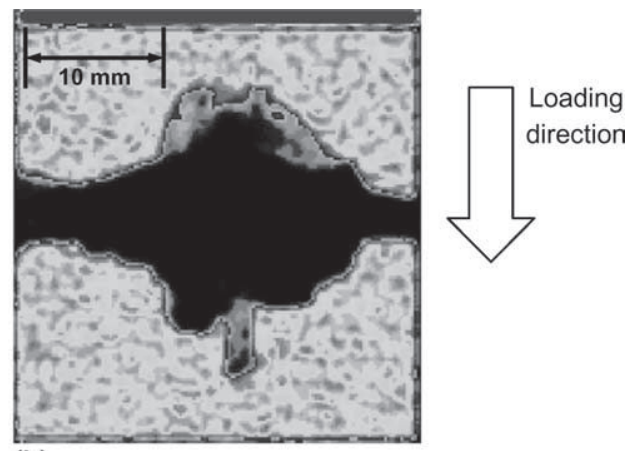

(b)

Fig. 6. C scan image of an impacted specimen damage: (a) before the compression test; (b) after the test.

Table 1

Elastic properties of the tape lamina AS4/3501 6. Properties supplied by the manufacturer

\begin{tabular}{llllllllll}
\hline Property & $E_{1}(\mathrm{GPa})$ & $E_{2}(\mathrm{GPa})$ & $E_{3}(\mathrm{GPa})$ & $v_{12}$ & $v_{13}$ & $v_{23}$ & $G_{12}(\mathrm{GPa})$ & $G_{13}(\mathrm{GPa})$ & $G_{23}(\mathrm{GPa})$ \\
\hline Value & 135.0 & 10.5 & 10.5 & 0.275 & 0.330 & 0.330 & 4.5 & 4.5 & 3.0 \\
\hline
\end{tabular}

In the ply with fibers perpendicular to the loading direction (Fig. 8(b)), the antibuckling plates produce rather higher stresses: $4 \%$ in the zones in contact with them and smaller stress concentrations in very localized areas. The stresses in all the plies in the centre of the specimen free surface (no contact with the antibuckling plates) were identical to those of the theoretical situation (the normal stress is $-104.5 \mathrm{MPa}$ in $0^{\circ}$ ply and $-24 \mathrm{MPa}$ in $\left.90^{\circ} \mathrm{ply}\right)$.

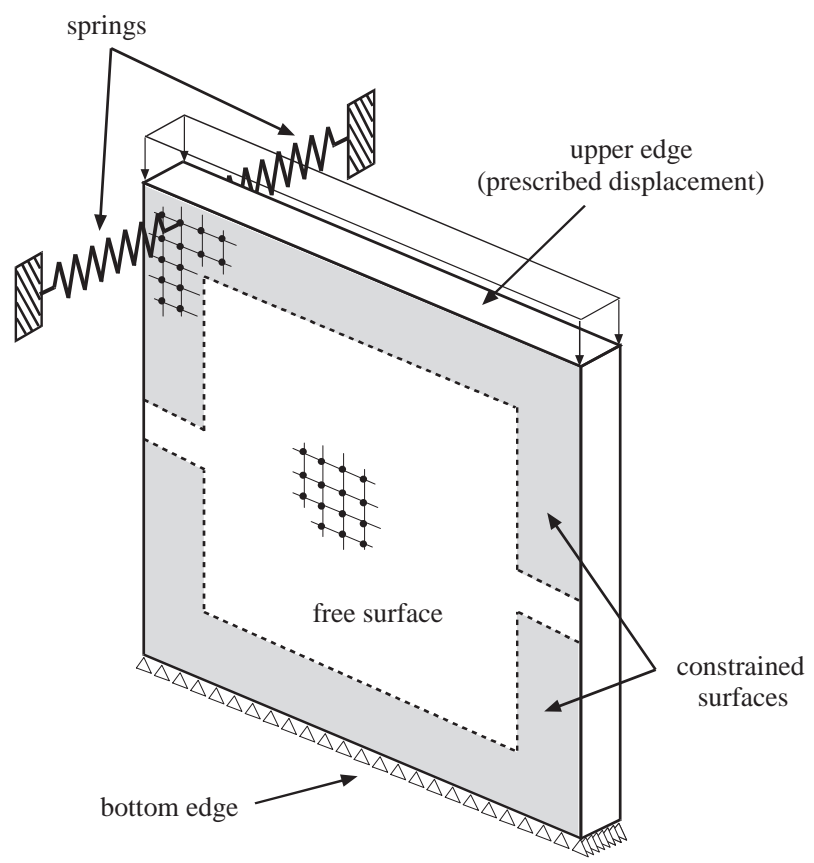

Fig. 7. Sketch of the finite element model for the constrained specimen.

\section{Materials and experimental tests}

\subsection{Materials}

The carbon fibre/epoxy composites used in this study were woven AGP193-PW/8552 (10 plies) and tape AS4/ 3051-6 with two lay-ups: cross-ply $[0 / 90]_{3 \mathrm{~S}}$ and quasiisotropic $[45 / 0 / 90]_{\mathrm{s}}$. The laminates were manufactured by SACESA in its facilities in Sevilla (Spain) from HEXCEL prepegs with a volumetric content of fibers of $60 \%$ and with the quality requirements this company uses for aeronautical applications. The thicknesses of the resulting laminates were: $2.2 \mathrm{~mm}$ for woven laminate, $2.2 \mathrm{~mm}$ for cross-ply laminate, and $1.6 \mathrm{~mm}$ quasi-isotropic laminate. The size of the specimens was $78 \times 78 \mathrm{~mm}$.

\subsection{Mechanical tests}

\subsubsection{Impact test}

The low-velocity impacts on the specimens were made with a drop weight tower, CEAST Fractovis 6785. The specimens were clamped around their edges by a $60 \mathrm{~mm}$ diameter ring, the circular support preventing any misorientation of the specimen. The semispherical tip of the impactor was of $20 \mathrm{~mm}$ diameter and its total mass $3.26 \mathrm{~kg}$.

The damage modes (matrix cracking, delamination and fiber fracture) caused by the impact varied with the impact energy and the laminate lay-up. A test of each laminate with a single energy would not clarify the material behaviour. Four impact energies, between the threshold level and that producing perforation of the laminates, were chosen. As these were of different thicknesses and lay-ups, different impact energies were used. All the tests were done at room temperature and 

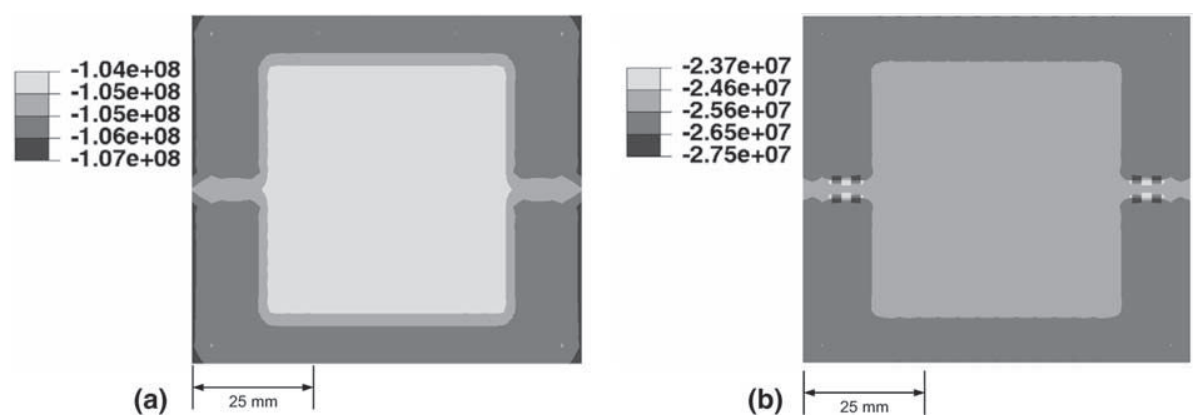

Fig. 8. Normal stresses in loading direction with antibuckling plate. (a) ply at $0^{\circ}$; (b) at $90^{\circ}$. Stress values in Pa.

three specimens of each kind of laminate and each impact energy were tested.

The impactor tip was instrumented with a load cell, so the force applied by the impactor on the specimen was recorded, as well as the initial velocity at the moment of impact. By using this record (force time) and assuming the hypothesis of permanent contact between the specimen and the impactor, the displacement of their contact point could be determined by successive integrations (Eq. (1)). And from the force displacement curve, the absorbed energy up to failure was obtained (Eq. (2)):

$$
\begin{aligned}
& x(t)=x_{0}+\int_{0}^{t}\left[v_{0}-\int_{0}^{\tau} \frac{F(\xi)-P}{m} \mathrm{~d} \xi\right] \mathrm{d} \tau, \\
& E(t)=\int_{0}^{t} F(\tau)\left[v_{0}-\int_{0}^{\tau} \frac{F(\xi)-P}{m} \mathrm{~d} \xi\right] \mathrm{d} \tau,
\end{aligned}
$$

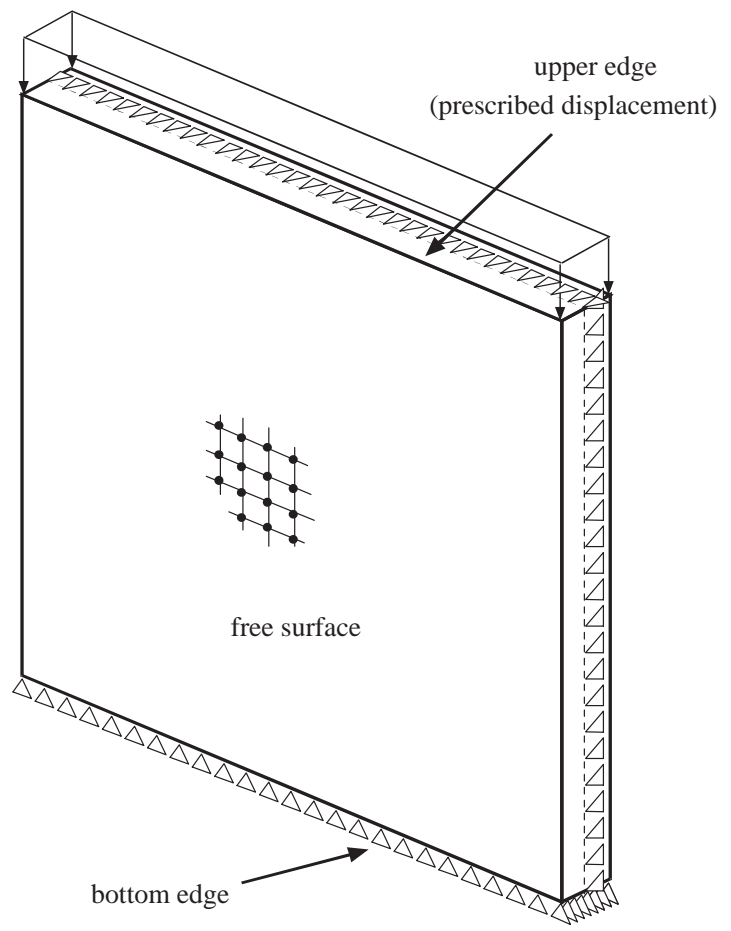

Fig. 9. Sketch of the finite element model of the unconstrained specimen. in which $F$ is the applied force, $\mathrm{m}$ the impactor mass, $P$ the impactor weight, $x_{0}$ the initial displacement of the specimen (considered nil), and $v_{0}$ the velocity at the instant of initiating the contact of the impactor on the specimen $\left(\begin{array}{ll}t & 0\end{array}\right)$.

\subsubsection{CAI test}

The CAI tests were done at room temperature, using an universal testing machine (Instron, model 8516), with a loading cell of $100 \mathrm{kN}$ and the CAI device developed for this study. The specimens were compressed at a constant displacement rate of $0.5 \mathrm{~mm} / \mathrm{min}$. Fifteen specimens of each lay-up were tested: three control specimens (unimpacted) and three impacted specimens at each of the energy levels, to obtain by comparison the loss of residual strength caused by the impact damage.

The force applied on the specimens was measured at each instant, and from the force time curve the failure force were obtained, which gave to determine the residual strength of the specimen from Eq. (3),

$\sigma_{\mathrm{c}}=\frac{F_{\max }}{b d}$,

in which $\sigma_{\mathrm{c}}$ is the compression strength, $F_{\max }$ the maximum force applied, $b$ the specimen width and $d$ its thickness.

\section{Results}

\subsection{Impact tests results}

The absorbed energy of the three laminate lay-ups (cross-ply, quasi-isotropic and woven), under different impact energies was calculated. The mean value as a function of the impact energy in each laminate is shown in Fig. 10.

In the three laminate lay-ups the absorbed energy was similar under the same impact energy, but this fact does not mean that the corresponding damaged areas were the same; in the cross-ply and quasi-isotropic laminates, the damaged area is larger than in the woven laminate. 


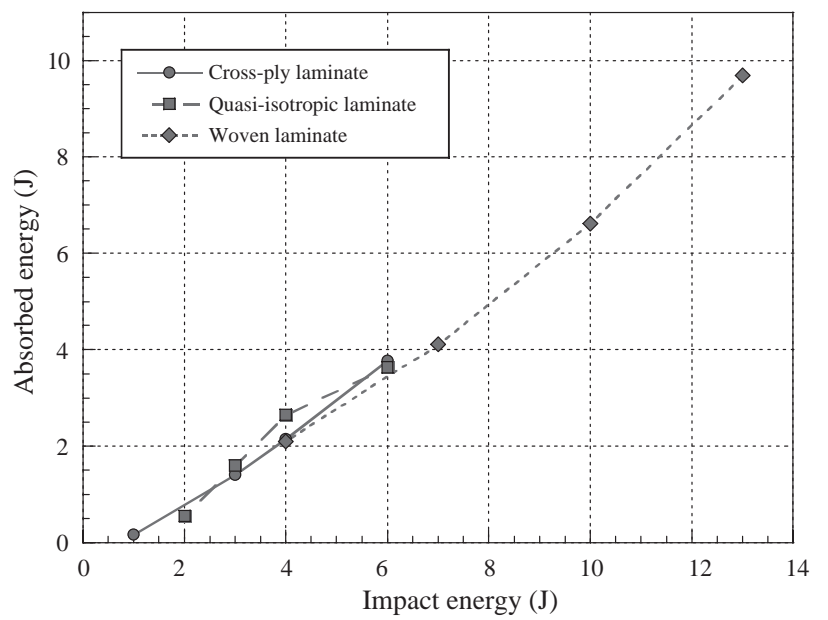

Fig. 10. Absorbed energy versus impact energy.

In the first two laminates, the delaminations are generated mainly by the differences between the bending stiffness of the adjacent plies, while in the woven laminate the reinforcement of all the plies has the same orientation so there is no difference between their bending stiffness. Also the weave structure of the reinforcement hinders the propagation of shear cracks and delaminations. More energy is needed to propagate cracks and consequently the damaged area in the woven laminate is smaller.

This was evident when the delamination area was measured by C-scan, a technique used in an earlier study of these laminates by the same work team [37] to measure the extension of the zone damaged by impact. Fig. 11 shows the delaminated areas of the impacted cross-ply and woven laminates subjected to the same energy (4 J). The delaminated area of the cross-ply was elliptical and larger than that of the woven laminate, in which the area was cross-shaped.

\subsection{CAI tests results}

Failure of damaged laminates under uniaxial compression load is caused by local buckling of the sublami-

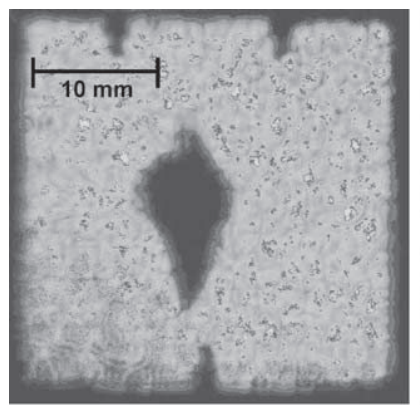

(a)

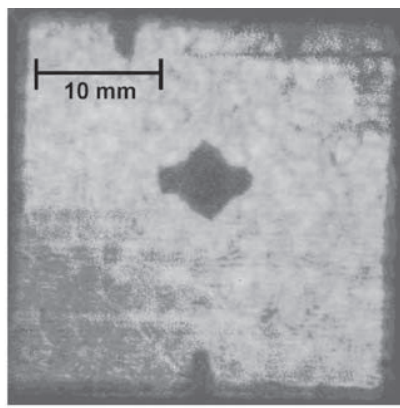

(b)
Fig. 11. C scan images of laminates impacted at $4 \mathrm{~J}$ : (a) cross ply and (b) woven [37]. nates originated in the impact. Delamination propagates mainly perpendicularly to the loading direction $\left(90^{\circ}\right)$, being smaller in $0^{\circ}$ direction (Fig. 5). The bending stiffness of the sublaminates is lower than that of a non-impacted laminate, so they buckle locally, and failure occurs under a lower load than in an unimpacted laminate.

The mean value and the standard deviation of the residual strength was determined in all the specimens of each tested laminate under the same impact energy. Dispersion was less than $10 \%$, even in the undamaged specimens, which are difficult to test in compression as they are susceptible to global buckling, misalignments, and high stress concentration factors at each end. These values of dispersion are similar to those found in other investigations $[9,14]$.

Fig. 12 shows the average compression strength of the test specimens as a function of the impact energy, including those of unimpacted specimens. From this Figure the effect of the impact energy on the residual strength was evaluated in the laminates tested. All showed the same trend towards the variation of the residual strength, a fairly sharp reduction at low impact energy and rather less as the impact energy was raised. The woven laminate is seen to have a greater residual strength under all the impact energies, and the quasi-isotropic the lowest (Fig. 12). The higher residual strength of the woven laminate is due to the control of shear cracking and delamination by the architecture of its reinforcement. Fig. 13 shows the normalized strength, which gives a better indication of the influence of the impact damage on the strength of the material. This property is defined as the ratio between the average strength of the specimens damaged by a given impact and the unimpacted ones.

The cross-ply laminate shows the greatest reduction of the normalized strength. At an impact energy of

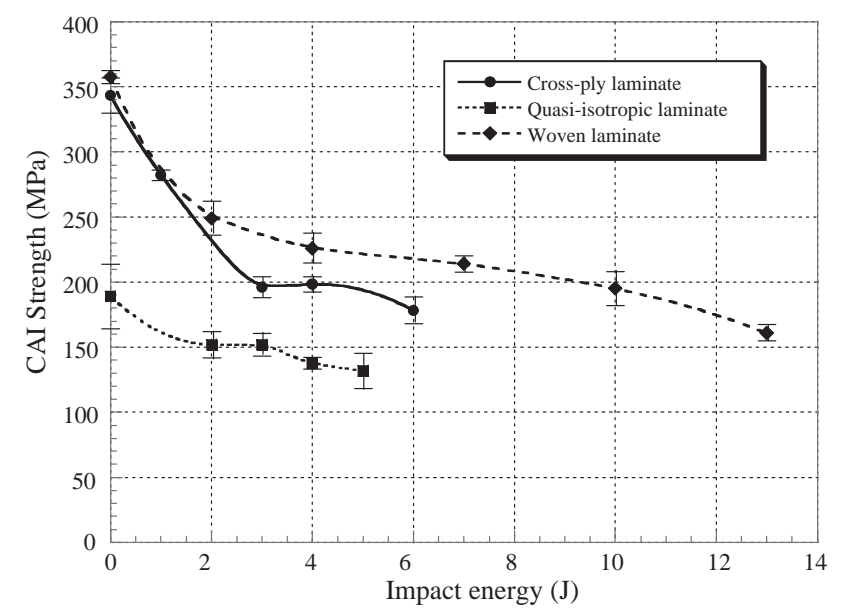

Fig. 12. Average values of compression residual strength as a function of the incident impact energy. 


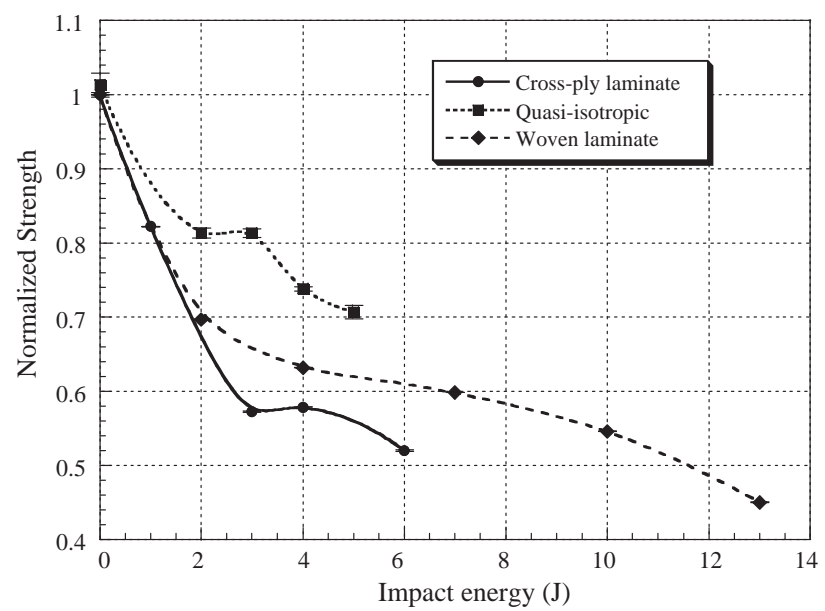

Fig. 13. Normalized compression strength as a function of impact energy.

$4 \mathrm{~J}$, the reductions of this strength are: $28 \%$ in quasiisotropic laminate, $37 \%$ in woven laminate and $43 \%$ in cross-ply laminate. The reduction may be due to the $90^{\circ}$ orientation of the inner plies, making the central sublaminate less stiff, more unstable, and liable to fail under a much lower load.

The smallest reduction of the normalized strength was observed in the quasi-isotropic laminate, even though its CAI strength is the lowest of all the impact energies (Fig. 13). This lower reduction may be due to the $\pm 45^{\circ}$ surface plies, which serve to protect the loadbearing $0^{\circ}$ plies against damage induced by impact [35].

The CAI strength values do not coincide with those of other works which used a quasi-isotropic laminate of different thickness and size, although the normalized residual strength of this laminate (Fig. 13) is similar: Srinivasan et al. [30] obtained values of 0.8 under $3 \mathrm{~J}$ and of 0.71 under $5 \mathrm{~J}$ impact energies.

\section{Conclusions}

There is no standard CAI set-up to test thin laminates. In this work, a new device was designed for CAI tests of small thin specimens, which does not require tabs neither to modify their geometry, thus simplifying the test. This device assures that laminate failure occurs by delamination propagation perpendicular to the loading direction, the propagation being less in the loading direction. A numerical simulation confirmed that the stress in a specimen with the antibuckling plates developed in this work reproduces that of the uniaxial compression state.

Impact tests were done in a drop weight tower over a range of energies to provide a wide picture of the material behaviour. All the tested laminates gave similar values of absorbed energy under the same impact condition but the damage modes were different; this implies a different residual material behaviour.

The highest value of compression strength under all the impact energies was that of the woven laminate, and the lowest that of the quasi-isotropic. The better compression strength of the woven laminate is attributed to the architecture of the reinforcement which controls the spread of damage. The quasi-isotropic showed the smallest reduction of the residual strength at all impact energies.

Quasi-isotropic laminates showed better damage tolerance than the other laminates, since their normalized strength reduction was the smallest at all the impact energies tested. This may be due to the surface plies, which protect the load-bearing $0^{\circ}$ plies against impact damage.

The smallest damage tolerance corresponds to the cross-ply laminate, in which the non-damaged plies $\left(90^{\circ}\right.$ plies) are the least stiff and therefore more unstable and liable to fail under lower stress.

\section{Acknowledgements}

The authors are indebted to the Spanish Comisión Interministerial de Ciencia y Tecnología (Project MAT-98/0273) for the financial support of this work.

\section{References}

[1] De Freitas M, Reis L. Failure mechanisms on composite specimens subjected to compression after impact. Compos Struct 1998;42(4):365 73.

[2] Xiong Y, Poon C, Straznicky PV, Vietinghoff H. A prediction method for the compressive strength of impact damaged com posite laminates. Compos Struct 1995;30(4):357 67.

[3] Symons DD, Davis G. Fatigue testing of impact damaged T300/ 914 carbon fibre reinforced plastic. Compos Sci Technol 2000;60:379 89 .

[4] Delfosse D, Poursartip A, Coxon BR, Dost EF. Non penetrating impact behaviour of CFRP at low and intermediate velocities. Compos Mater: Fatigue Fract 1995;5:333 50. ASTM STP 1230.

[5] Sjoblom PO, Hartness JT, Cordell TM. On low velocity impact testing of composite materials. J Compos Mater 1988;22:30 52.

[6] Baker AA, Jones R, Callinan RJ. Damage tolerance of graphite/ epoxy composites. Compos Struct 1985;4(1):15 44.

[7] Abrate S. Impact on composite structures. New York: Cam bridge university press; 1998

[8] Cantwell WJ, Curtis P, Morton J. An assessment of the impact performance of CFRP reinforced with high strain carbon fibres. Compos Sci Technol 1986;25(2):133 48.

[9] Prichard JC, Hogg PJ. The role of impact damage in post impact compression testing. Composites 1990;21(6):503 11.

[10] NASA. Standard test for toughened resin composites. NASA Reference Publication 1092; 1983.

[11] Boeing. Advanced composite compression test. Boeing Specifica tion Support Standard BSS 7260; 1988.

[12] SACMA Recommended Methods SRM 294. Suppliers of Advanced Composites Materials Association; 1994. 
[13] Curtis PT. CRAG Test methods for the measurements of the engineering properties of fibre reinforced plastics. Royal Aero space Establishment Technical Report TR88012; 1988.

[14] Hawyes VJ, Curtis PT, Soutis C. Effect of impact damage on the compressive response of composite laminates. Compos Part A: Appl Sci Manuf 2001;32(9):1263 70.

[15] Duarte A, Herszberg I, Paton R. Impact resistance and tolerance of interleaved tape laminates. Compos Struct 1999;47(1 4):753 8 .

[16] Ambur DR, Kemmerly HL. Influence of impactor mass on the damage characteristics and failure strength of laminated compos ite plates. In: Proceedings of the 39th AIAA/ASME/ASCE/ASC structures, structural dynamics and materials conference, Long Beach, CA, USA; 1998.

[17] Zhou G. The use of experimentally determined impact force as a damage resistance and tolerance of composite structures. Compos Struct 1998;42(4):375 82 .

[18] Dost EF, Ilcewicz LB, Avery WB, Coxon BR. Effects of stacking sequence on impact damage resistance and residual strength for quasi isotropic laminates. In: O'Brien TK, editor. Composite Materials: Fatigue and Fracture, vol. 3, Philadelphia; 1991 ASTM STP 1110.

[19] Dorey G, Bishop SM, Curtis PT. On the impact performance of carbon fibre laminates with epoxy and PEEK matrices. Compos Sci Technol 1985;23(3):221 37.

[20] Robinson JH. Orbital debris impact damage to reusable launch vehicles. Int J Impact Eng 1999;23:783 94.

[21] Rivers HK. Conformal cryogenic tank trade study for reusable launch vehicles. Space Technology and Application International Forum, Alburquerque, New Mexico, USA; 1999.

[22] Sawyer JW, Bush H. Experimental investigation of a graphite composite intertank section for a reusable launch vehicle. Space Technology and Applications International Forum (Staif, 98), Alburquerque, New México, USA; 1998.

[23] Abumeri GH, Kuguoglu LH, Chamis CC. Composite fan blade design for advanced engine concepts; 2004. NASA/TM 2004 212943.

[24] Nettles AT, Hodge AJ. Compression after impact testing of thin composite materials. In: Proceedings of the $23 \mathrm{rd}$ international SAMPE technical conference; 1991. p. 17783.
[25] Liu D, Raju BB, Dang X. Size effects on impact response of composite laminates. Int J Impact Eng 1998;21(10): 83754 .

[26] Sjoblom PO, Hwang B. Compression after impact: The \$5 000 data point!. International SAMPE Symposium and Exhibition, vol. $34 ; 1989$; p. 141121

[27] Corum JM, Battiste RL, Ruggles Wrenn MB. Low energy impact effects on candidate automotive structural composites. Compos Sci Technol 2003;63:755 69.

[28] Breikin NL, Gurdal Z, Griffin OH. Compression of laminated composite beams with initial damage. J Reinf Plast Compos 1993;12:813 24.

[29] Habib FA. A new method for evaluating the residual compression strength of composites after impact. Compos Struct 2001;53:309 16 .

[30] Srinivasan K, Jackson WC, Hinkley JA. Response of composite materials to low velocity impact. Int SAMPE Symp 1991;36:850 62.

[31] Bishop SM. The mechanical performance and impact behavior of carbon fibre reinforced PEEK. Compos Struct 1985;3(3 ):295 318

[32] Kim J, Shioya M, Kobayashi H, Kaneko J, Kido M. Mechanical properties of woven laminates and felt composites using carbon fibers. Part 1: In plane properties. Compos Sci Technol 2004;64:2221 9.

[33] Kim JK, Sham ML. Impact and delamination failure of woven fabric composites. Compos Sci Technol 2000;60:745 61 .

[34] Bibo GA, Hogg PJ. Damage tolerance of continuous fibre composites: material and environmental effects. Key Eng Mater 1998;141 143:93 126

[35] Cantwell WJ, Morton J. The impact resistance of composite materials a review. Composites 1991;22(5):347 62 .

[36] ABAQUS User's manual, version 6.4.1, Hibbiyy, Karlsson and Sorensen, Inc.; 2003.

[37] Gomez del Rio T, Sanchez Saez S, Barbero E, Zaera R, Lopez Puente J, Navarro C. Impact behaviour of CFRPs at cryogenic temperatures. In: Proceedings of eighth annual international conference on composites engineering (ICCE/8), Tenerife; August 2001. p. B23 6 . 